\title{
The numerical relations and arithmetic disturbances of aphasic Greek population (a factor analysis) Dionysios Tafiadis*1, Konstantinia Arampatzi ${ }^{2}$, Eupraxia Tsanousa ${ }^{3}$ and Maria Tafiadis 4
}

Address: ${ }^{1}$ Department of Speech Language Therapy, Technological Institute of Ioannina, Ioannina Greece, ${ }^{2}$ Speech and Language Rehabilitation Center, Larisa, Greece, ${ }^{3}$ Department of primary education, University of Ioannina, Ioannina, Greece and ${ }^{4}$ Department of Mathematics, University of Patras, Patras, Greece

* Corresponding author

from International Society on Brain and Behaviour: 3rd International Congress on Brain and Behaviour

Thessaloniki, Greece. 28 November - 2 December 2007

Published: 17 April 2008

Annals of General Psychiatry 2008, 7(SuppI I):SI 98 doi:10.1 186/I744-859X-7-SI-SI 98

This abstract is available from: http://www.annals-general-psychiatry.com/content/7/SI/SI 98

(c) 2008 Tafiadis et al.; licensee BioMed Central Ltd.

\section{Background}

Purpose of the present study was to record the numerical relations and arithmetic disturbances that occurs in adult's aphasia for the Greek population. This record was made by the use of the Minnesota test for the differential diagnosis of aphasia (M.T.D.D.A) which was originally created by Hildred Schuell in 1946 [1] and was later revised in 1972 by Jenkins, Jimenes-Pabon, Shaw and Sefer (1975) [2] and preliminary standardized for the Greek language by Arampatzi and Tafiadis (2006) [3].

\section{Materials and methods}

The battery is used as diagnostic scale for the differential diagnosis of adult aphasia and measures the language skills in the aphasic population. The fifth part is specialized to track numerical relations and arithmetic disturbances in correlation with education level of the participants, and was administered to 45 aphasic participants recruited from Greek health settings, aged 37 - 83 years.

\section{Results}

Statistical analysis of the data revealed that the results obtained are generally consistent with the results reported in other countries. No statistically significant differences were found between the results obtained for the Greek population and the results reported in the USA population in all visual subtests.

\section{Conclusions}

The battery appears to be sensitive to adult aphasic symptomatology for the numerical relations and arithmetic disturbances in the Greek population and presents satisfactory criterion among the types of aphasia, as the aphasic participants assessed demonstrated clear patterns of deficit.

\section{References}

I. Schuell H, Jenkins JJ, Jimenes-Pabon E: Aphasia in adults: Diagnosis, prognosis and treatment. New York: Harper and Row; 1964.

2. Jenkins Jj, Jimenes-Pabon E, Shaw ER, Sefer W: Schuell's aphasia in adults : Diagnosis, prognosis and treatment. New York: Harper and Row; 1975.

3. Tafiadis D: Preliminary standardization of the Minnesota test for differential diagnosis of adult aphasia in the Greek population. Annals of General Psychiatry 2006, 5(SuppI I):SI83. 